\title{
RISK MISPERCEPTIONS OF STRUCTURED FINANCIAL PRODUCTS WITH WORST-OF PAYOUT CHARACTERISTICS REVISITED
}

Nobuyuki Hanaki

Revised November 2021

September 2021

The Institute of Social and Economic Research

Osaka University

6-1 Mihogaoka, Ibaraki, Osaka 567-0047, Japan 


\title{
Risk misperceptions of structured financial products with worst-of payout characteristics revisited*
}

\author{
Nobuyuki Hanaki ${ }^{\dagger}$ \\ forthcoming in \\ Journal of Behavioral and Experimental Finance
}

November 5, 2021

\begin{abstract}
In this paper, we reexamine a bias revealed by Kunz et al. (2017) regarding structured financial products known as barrier reverse convertibles (BRCs) with worst-of payout characteristics. Namely, using a nonincentivized survey of investor risk perceptions, Kunz et al. (2017) found that when safe assets are included with risky assets to provide the underlying assets of a BRC, investors erroneously perceive a lower risk for the BRC when in fact it becomes higher. We confirm the same bias among student participants using the results of an incentivized experiment. However, we do not observe any similar bias among finance professionals.
\end{abstract}

\section{Keywords: Experiment, Barrier Reverse Convertibles}

JEL Code: G11, G41, C99

*This work was supported by the Japan Society for the Promotion of Science, Grant-in-Aid for Scientific Research, Nos. 18K19954, and 20H05631, and the Joint Usage/Research Center, Institute of Social and Economic Research, Osaka University. The experiments reported in the paper were approved by the Institutional Review Board of the Institute of Social and Economic Research, Osaka University. We thank Claude Messner for sharing the Qualtrics questionnaire used in Kunz et al. (2017), Yuta Shimodaira for an excellent research assistance, and Takeshi Murooka, Claude Messner, Martin Wallmeier, Katsuhiko Okada, Kentaro Iwatsubo, and anonymous reviewers for comments on earlier draft.

${ }^{\dagger}$ Institute of Social and Economic Research, Osaka University. E-mail: nobuyuki.hanaki@iser.osakau.ac.jp 


\section{Introduction}

Since the introduction in 1990's, the market of retail structured financial products has grown tremendously. According to SRP, there are currently more than 31 million products with total sales of more than 12 trillion USD.11 While European market, which is the oldest, has been the largest market for a long time, now the Asia-Pacific market has surpassed European market $\left.\right|^{2}$

While being popular, these products are so complex that one, including regulators, may ask whether investors correctly understand and assess the risk associated with these products (Hunt et al. 2015). In fact, it is possible that complexity of these products are used to take advantage of behavioral biases of investors such as their focusing on headline returns. Indeed, based on their analyses of 55,000 products issued in Europe between 2002 to 2010, Célérier and Vallée (2017) suggests that the more complex and risker products with higher headline rates appear more profitable to the financial institutions distributing them. Similarly, Vokata (2021) shows that based on the analyses of her sample of more than 28,000 yield enhancement products issued between 2006 to 2015, these products in fact generate negative returns both ex ante and ex post due to their embedded fees despite of the attractive yields they offer. Henderson and PearSon (2011) who analyze 64 products, and Bernard et al. (2011) who focus on locallycapped investment products, both reach a similar conclusion. Understanding the impact of various behavioral/psychological bias that influence investors when assessing the risk associated with these complex financial products is, therefore, important in designing regulator framework to protect investors from being exploited.

\footnotetext{
${ }^{1}$ https://www. structuredretailproducts. com/data last accessed on Sep. 27, 2021. ${ }^{2}$ See, "A short history of structured products" by SRP (https://www. structuredretailproducts.com/srp-academy/structured-products-history, last accessed on Sep. 27, 2021.)
} 
In this paper, we experimentally reexamine a bias revealed by Kunz et al. (2017) regarding investor risk perceptions regarding a type of structured financial products known as barrier reverse convertibles (BRCs) with worst-of payout characteristics. Namely, Kunz et al. (2017) found using an online survey that when relatively safe assets are added to risky assets that provide the underlying assets of a BRC, investors erroneously perceive the risk of the BRC as lower when in fact it becomes higher.

BRCs are a popular type of structured financial product (Rieger, 2012; Hens and Rieger, 2014; Kunz et al., 2017) that offers a fixed interest payment and some protection of capital against downside risk in exchange for foregoing any possible capital gain.

Typically, the BRC has a set of underlying assets (such as stocks) and its repayment of the invested amount at maturity depends on the price movements of these underlying assets during the contracted period. In a typical example, investors will receive back cash equal to their nominal invested amount if one of the following two conditions are met: (1) none of the prices of the underlying assets have fallen below their respective preset barrier prices during the contracted period, and (2) the prices of all the underlying assets are above their respective initial prices at maturity. Note that barrier prices are set well below their initial prices to offer some capital protection against potential price falls. However, if neither of these two conditions is satisfied, investors will receive only the fixed number of shares of the worst performing asset (i.e., the asset with the lowest price relative to its initial price) from among the underlying assets. The number of shares that investors receive is then equal to their nominal invested amount divided by the asset's initial price.

From this description, investors then forego any capital gain (from any price increase in the underlying assets) by investing in a BRC. For this reason, Hens and Rieger (2014) argues that after taking fees into account, investment in BRCs cannot be explained by 
standard expected utility maximizing models, rather only behavioral models such as prospect theory (Kahneman and Tversky, 1979) can ${ }^{3}$

Note, however, that repaying investors with the worst performing asset implies that having more underlying assets only increases the downside risk they must bear. Thus, it is puzzling why such products are popular among investors even from the point of view of prospect theory. To account for this apparent anomaly, Rieger (2012) argues that investors' behavioral biases, such as their use of availability heuristics (e.g., assessing risk based on their familiarity with the underlying asset), increases the perceived attractiveness of these products. Elsewhere, Kunz et al. (2017) offers an interesting explanation by referring to a misconception known as "dieter's paradox" (Chernev, 2011) "whereby people erroneously believe that eating healthy foods in addition of unhealthy ones can decrease a meal's calorie count" (Chernev, 2011, p.178), Kunz et al. (2017) hypothesize that when relatively safe assets are added to risky assets to serve as the underlying assets of a $\mathrm{BRC}$, investors erroneously perceive the risk of the $\mathrm{BRC}$ becomes lower when it is, in fact, higher.

Kunz et al. (2017) confirm this hypothesis using an online survey of active capital market investors, revealing that investors consider the likelihood of receiving their invested cash back at maturity being significantly higher with a BRC comprising two safe and one unsafe stocks $5^{4}$ than with a BRC covering just one unsafe stock. On average, the differences in the average estimated probability of repayment are $6.12 \%$ and $13.64 \%$ (both significant at the $1 \%$ level) for investors with and without experience of investing

\footnotetext{
${ }^{3}$ Indeed, investors focusing on likelihood of making / avoiding loss seems to be a natural way for humans to perceive risks. Holzmeister et al. (2020) conducted a large-scale survey experiment on riskperception in nine countries (Brazil, China, Germany, India, Japan, Russia, UK, USA, and South Africa) with more than 2000 financial professionals and 4500 lay people. They find that the skewness of the return distribution, not the variance, is the only moment that systematically affects respondents perceptions of financial risk, although the latter is the main measure of the financial risk used in analyses.

${ }^{4}$ Where safe and unsafe stocks refer to stocks with low and high price volatility, respectively.
} 
in BRCs within 5 years of the survey, respectively (Kunz et al., 2017, p.72, Table 4).

This dieter's paradox is thought to arise because of the tendency of people to categorize food items into opposing categories (good vs bad), and to evaluate the total impact of the combination of these items by averaging rather than adding their individual impacts (Chernev and Gal, 2010). Consistent with this view, Kunz et al. (2017, p.72, Table 4) finds that this misperception is not simply because the number of underlying assets is larger. The average estimated probability of a cash repayment for a BRC with three safe underlying asset is $2.76 \%$ lower than that of one safe underlying asset (significant at the $1 \%$ level), while that of BRCs with three unsafe underlying assets is $6.48 \%$ lower than that of one unsafe underlying asset (again significant at the $1 \%$ level).

In this paper, we reexamine the finding in Kunz et al. (2017) by employing an incentivized experiment. Because the survey participants used by Kunz et al. (2017) did not face any monetary consequences concerning the accuracy of their stated estimates, we consider the results there may suffer from hypothetical bias.5 Further, we are not only interested in participant risk misperceptions, but also whether such misperceptions impact upon investment behavior. Thus, in our experiments, participants are repeatedly asked to decide how much of their endowment to invest across various BRCs. These participants, if chosen for performance-based payment, are then paid according to the outcomes of their investment decisions.

Moreover, because BRCs are complex financial products, even in the highly simplified version we constructed for our experiment, by conducting an experiment using university students without much experience in investing, even those from a highly selective university, may not provide us with useful insights about the behaviors of active

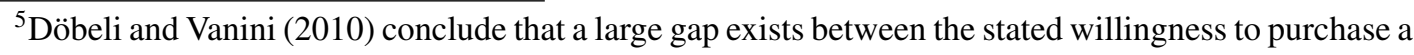
structured financial product in a hypothetical survey and the revealed purchase decision using investment data.
} 
investors. Therefore, we repeat the same experiment using a sample of certified financial analysts (CFAs).

We obtain support for the findings in Kunz et al. (2017) only among student participants. For these participants, the average amount invested in BRCs with three underlying assets, comprising one asset with low price volatility and two assets with high price volatility, is significantly higher than the minimum amount invested among three BRCs where only one constitutes three underlying assets. For the CFAs, however, the average amount invested in the former is not significantly different from the latter. This suggests that the effect of probability misperception a la the "dieter's paradox" is significant only among naive investors, not more sophisticated investors.

The rest of the paper is organized as follows. Section 2 describes the experiment, followed by the results in Section 3 , Section 5 concludes.

\section{Experiment}

In our experiment, participants repeatedly make an investment decision. There are 14 investment tasks in total. In each task $(t)$, each participant $(i)$ is given 1,000 experimental currency units (ECUs) from which they choose to invest $\operatorname{In} v_{t}^{i} \in\{0,100, \cdots, 900,1000\}$ ECUs in the financial product described in the task. The amount not invested will be kept as cash and will be included in the final payment (but cannot be used to invest in financial products presented in other investment tasks). The invested amount will generate a return according to the description of the financial product ${ }^{6}$

These financial products are either investment in the stock of one of four hypothetical companies whose daily prices for 250 business days prior to the investment day (day

${ }^{6}$ An English translation of our experiment can be found at https://bgt.au1.qualtrics. com/jfe/form/SV_2n8rx9QEDzRJ1Ai 
Figure 1: Four hypothetical stocks

Stocks with low price volatility

Stock 1

Stock 2
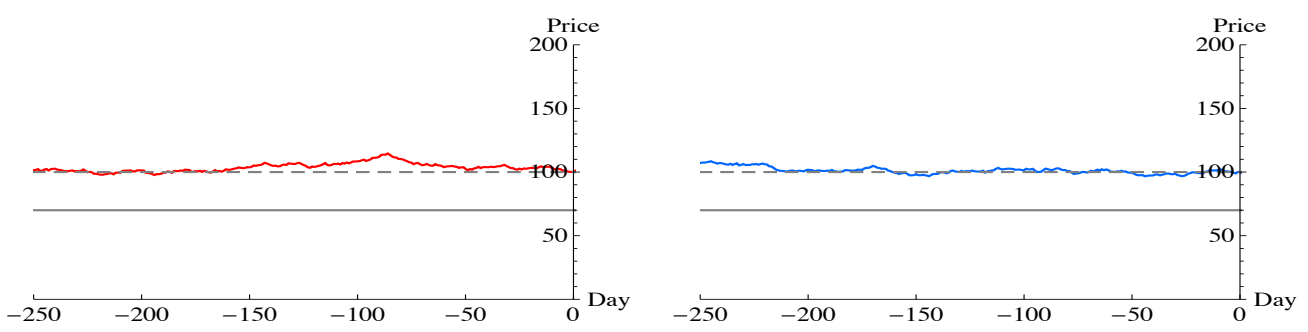

Stocks with high price volatility

Stock 3

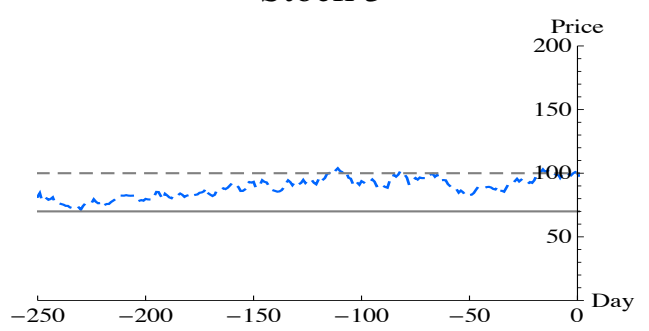

Stock 4

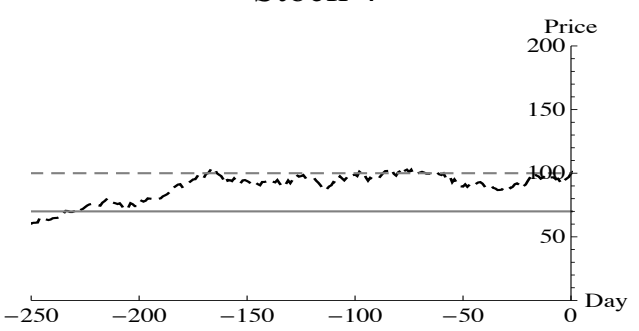

Note: The initial price (100) as well as a barrier price (70) are shown in addition to the stock price.

0) are shown in Figure 1, or a BRC based on either one or three of these four hypothetical companies. These products are all hypothetical in that the four stock prices are generated by simulating a model, and all the stock prices are normalized so that their initial prices (i.e., the prices at the investment day (day 0) are all equal to 100 . The investment horizon is 1 year (250 business days) for all 14 financial products.

As shown in Figure 1, two of these four companies are characterized by high stock price volatilities (Stocks 3 and 4), and the remaining two are characterized by low stock price volatilities (Stocks 1 and 2) $]^{7}$

\footnotetext{
${ }^{7}$ In the model, the price dynamics follow a geometric Brownian motion with an expected daily return of $0 \%$ and a standard deviation of $(s d / \sqrt{250}) \%$ where $s d=10$ and $s d=30$ for low and high volatility stocks, respectively. Participants are informed that the stocks and their prices (and hence returns) are
} 
Four of the 14 financial products are simply the stock of one of these four companies. Each unit of stock can be bought at 100 ECUs on the investment day and generates a dividend income of 5 ECUs. The payoff for participants investing $\operatorname{In} v_{t}^{i}$ ECUs in the stock is simply

$$
1000-\operatorname{In} v_{t}^{i}+5 \times \frac{\operatorname{In} v_{t}^{i}}{100}+P_{s} \frac{\operatorname{In} v_{t}^{i}}{100}
$$

where $P_{s}$ is the realized price of the stock $s$ at maturity, i.e., after 250 simulated business days.

The remaining ten financial products are BRCs. Six of these have a single stock as their underlying asset and four have three stocks (one low price volatility stock and two high price volatility stocks) as their underlying assets.

All these BRCs have the following features:

- $5 \%$ interest on the invested amount (Inv) is paid in cash at maturity.

- If the price(s) of the underlying stock(s) always stay(s) above the barrier price (either 70 or 50) until maturity, the invested amount is returned in cash at maturity (case 1).

- Alternatively, if the price (of at least one of the underlying stocks) falls below the barrier before maturity at least once, then what investors receive at maturity depends on the (lowest) price of the underlying $\operatorname{stock}(\mathrm{s})$ at the maturity. If the (lowest) price of the underlying stock(s) is

- greater or equal to 100 (i.e., the initial price), the invested amount is returned in cash (case 2).

hypothetical, but are not informed how the prices are generated. 
- less than 100, then Inv/100 units of the stock (with the lowest price at the maturity) is returned to the investors (Case 3).

The BRCs using three stocks as their underlying asset have "worst-of" payout characteristics because their payout then depends on the worst-performing stock.

In our experiment, when Case 3 arises, the payoff of participants for this investment task is computed based on the realized price of the received stock at maturity. Thus, the payoff for participants from investing $\operatorname{In} v_{t}^{i}$ ECUs in the $\mathrm{BRC}$ is:

$$
\begin{array}{lr}
1000+\frac{5}{100} \times \operatorname{In} v_{t}^{i} & \text { in case } 1 \text { or } 2 \\
1000-\operatorname{In} v_{t}^{i}+\frac{5}{100} \times \operatorname{In} v_{t}^{i}+P_{s} \frac{\operatorname{In} v_{t}^{i}}{100} & \text { in case } 3
\end{array}
$$

where $P_{s}$ is the realized (lowest) price of the underlying stock(s) at the maturity date. Table 1 summarizes the features of the 14 financial products considered in our experiment.

To isolate the effects of the protection offered by BRCs and the associated costs for foregoing the possibility of capital gain on investment decisions, we intentionally set the remaining aspects, that is, the rate of interest/dividend earning as well as (the absence of) the possibility of liquidation before maturity, the same for the investment in stocks and the BRCs.

Each participant receives a participation fee of either 500 JPY (for students) or 1,000 JPY (for CFAs). In addition, participants completing the experiment have a $10 \%$ chance of being selected for an additional financial reward. If a participant is selected for the additional reward at the end of the experiment, one of the 14 investment tasks is chosen randomly, and the participant paid according to the ECUs earned in the selected task 
Table 1: Fourteen financial products

\begin{tabular}{|c|c|c|c|}
\hline Product & Underlying stock & Interest / dividend & Barrier price \\
\hline Stock $_{L V 1}$ & Stock 1 & Dividend 5 ECUs / unit & n.a. \\
\hline Stock $_{L V 2}$ & Stock 2 & Dividend 5 ECUs / unit & n.a. \\
\hline Stock $_{H V 1}$ & Stock 3 & Dividend 5 ECUs / unit & n.a. \\
\hline Stock $_{H V 2}$ & Stock 4 & Dividend 5 ECUs / unit & n.a. \\
\hline $\mathrm{BRC}_{L V, 70-1}$ & Stock 1 & $5 \%$ interest on invested amount & 70 \\
\hline $\mathrm{BRC}_{L V, 70-2}$ & Stock 2 & $5 \%$ interest on invested amount & 70 \\
\hline $\mathrm{BRC}_{H V, 70-1}$ & Stock 3 & $5 \%$ interest on invested amount & 70 \\
\hline $\mathrm{BRC}_{H V, 70-2}$ & Stock 4 & $5 \%$ interest on invested amount & 70 \\
\hline $\mathrm{BRC}_{H V, 50-1}$ & Stock 3 & $5 \%$ interest on invested amount & 50 \\
\hline $\mathrm{BRC}_{H V, 50-2}$ & Stock 4 & $5 \%$ interest on invested amount & 50 \\
\hline $\mathrm{W}-\mathrm{BRC}_{70-1}$ & Stocks 1,3 , and 4 & $5 \%$ interest on invested amount & 70 \\
\hline $\mathrm{W}-\mathrm{BRC}_{70-2}$ & Stocks 2,3 , and 4 & $5 \%$ interest on invested amount & 70 \\
\hline W-BRC $50-1$ & Stocks 1,3 , and 4 & $5 \%$ interest on invested amount & 50 \\
\hline $\mathrm{W}-\mathrm{BRC}_{50-2}$ & Stocks 2,3 , and 4 & $5 \%$ interest on invested amount & 50 \\
\hline
\end{tabular}

Note: For all the products, the unit price at the date of investment is 100 .

with an exchange rate of 1 ECU equals either 5 JPY (for students) or 10 JPY (for the CFAs). Participants are paid using an Amazon gift card (e-mail version).

In addition to these investment tasks, the participants are asked to estimate the frequency (out of 1,000) in which a BRC does not return the principal in cash, but in units of the underlying stock instead, under three barrier prices (70, 60, and 50). For this task, participants are informed that the underlying stock prices are generated by simulating a model that is well known to capture real stock price movements and are also shown five realizations of such simulations (Figure 2).

If a participant is chosen for the additional financial reward, one of the three estimates is chosen randomly for an additional reward. If the chosen estimate falls within $10 \%$ of the realized frequency, the participant is given 100 ECUs in addition to the reward earned in the randomly selected investment task. Participants are not informed 
Figure 2: Graph shown for the estimation task

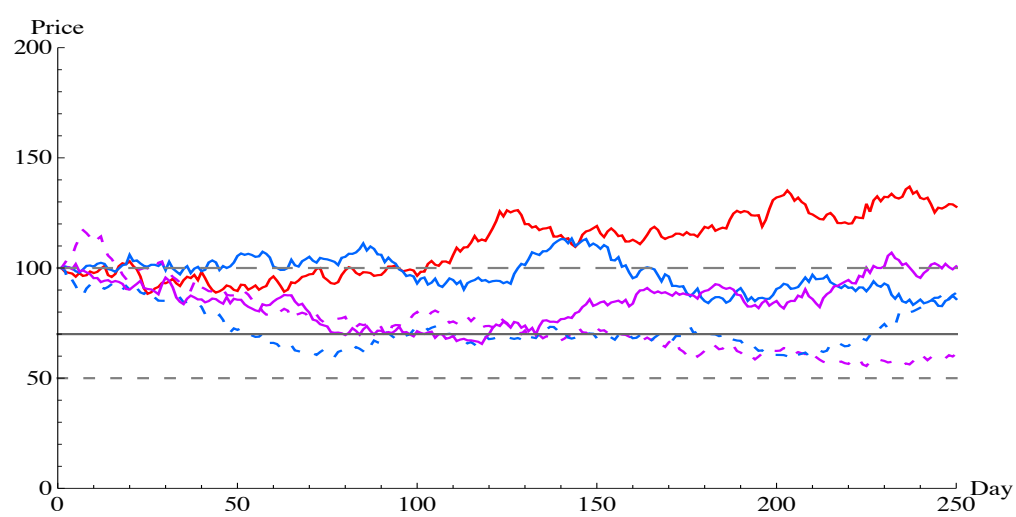

Note: initial price (100) as well as two barrier prices (70 and 50) are also shown.

about this task until they complete all 14 investment tasks.

The results of the selected investment and estimation tasks were shown to those participants selected to receive these additional rewards at the very end of the experiment (after the postexperiment questionnaire). After the estimation task, a questionnaire including questions on demographics and the participant's knowledge and experience in investing in a structured financial product is administered. For students, we also implemented a financial literacy quiz taken from Fernandes et al. (2014). See Appendix C for the questionnaire.

\section{Results}

The online experiment was conducted in August to September $20218^{8}$ An invitation email was sent on Monday, August 30, 2021, to 195 students at Osaka University and 110 CFAs that had previously participated in an earlier finance-related online experiment

\footnotetext{
${ }^{8}$ The experiment was implemented using the Qualtrics survey platform (www. qualtrics.com).
} 
and who had agreed to participate in a future experiment. The deadline to participate and complete the experiment was set at 23:59 on September 3, 20219.9 Among those invited, 87 students and 84 CFAs completed the experiment. On average, the participants took 1,500 seconds to complete the experiment. The average score of the financial literacy quiz of these 87 students is 8.5 (with the standard deviation of 2.19 , and the minimum and the maximum scores are 2 and 12, respectively.)

Of the 87 students and 84 CFAs, 3 students and 38 CFAs declared that they had some knowledge of BRCs. Most of the participants, comprising 87 students and 81 CFAs, reported that they had not purchased any BRCs in the past 5 years. 10

To obtain reliable results, we report here the results of the analyses based on the sample excluding those participants that had spent an extremely short time (shortest $10 \%$, less than 586 seconds) or an extremely long time (longest $10 \%$, more than 6,527 seconds) to complete the experiment. We also excluded from the analyses those participants whose submitted estimates in the estimation task were not monotonically decreasing as the barrier price became lower. ${ }^{11}$ Thus, we have 63 students and 64 CFAs in our data used in the results presented below. We report the results without excluding these participants from the analyses in Appendix $\mathrm{A}$. The results based on the full sample are like those we report in the main text.

\footnotetext{
${ }^{9}$ Participants were asked to complete the experiment without taking a long break in the middle; however, the software was configured so that participants could return to the experiment anytime within 24 hours from the start of the experiment. The participants were also asked to participate in the experiment only once and the software was configured so that each participant could access the experiment only once from the same browser. If they wished, however, the participants could access the experiment multiple times by using different browsers or different devices. To check where participants responded on multiple occasions, we kept a record of participant IDs and dropped one participant who completed the experiment twice from the sample.

${ }^{10}$ Two CFAs declared having bought structured financial product, not necessary BRCs, once and 1 CFA declared having bought more than eight times in the past 5 years.

${ }^{11}$ Recall that participants submit their estimates of the probability of receiving stocks instead of cash at the maturity. We allow for the estimated probabilities to remain constant.
} 
Figure 3: Amount invested in stocks vs BRCs with a single underlying asset.
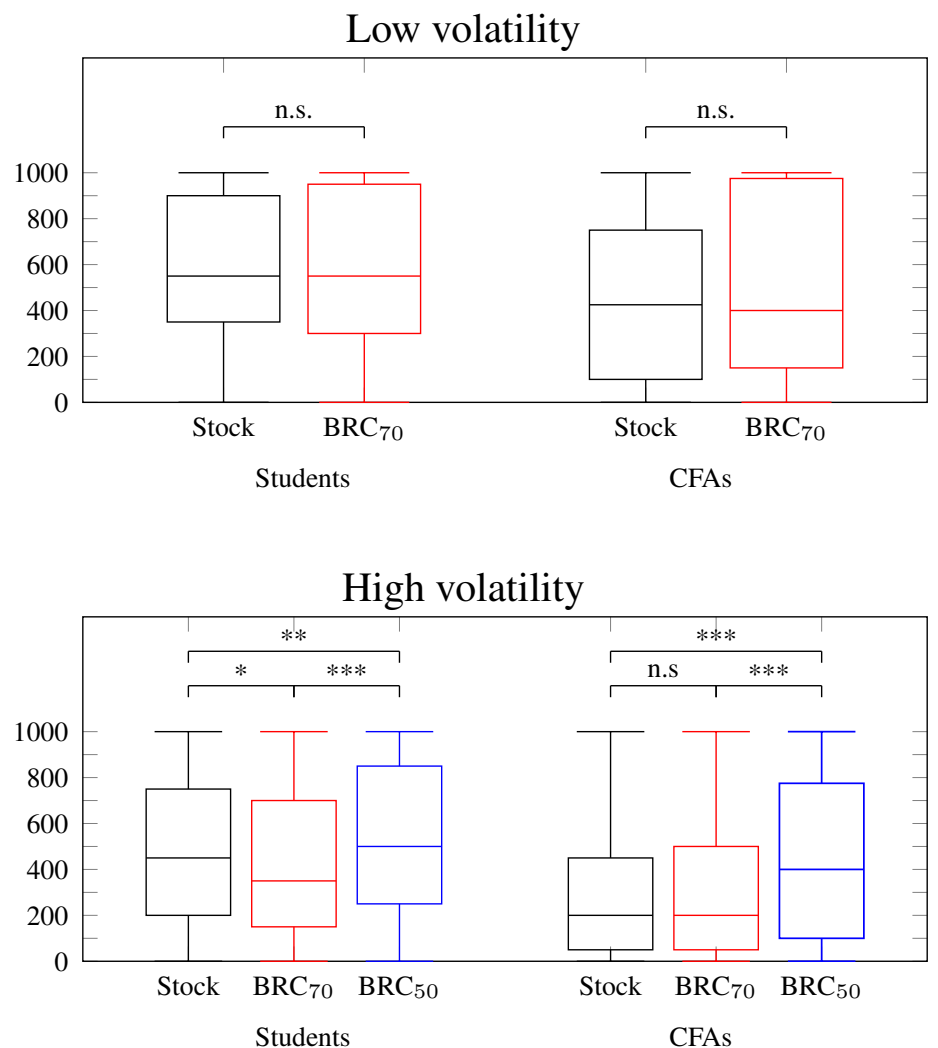

$* * *, * *$, and $*$ denote statistically significant differences at the $1 \%$, $5 \%$, and $10 \%$ significance level using the two-tailed Wilcoxon signedrank (WSR) test, respectively.

\subsection{Investment in stocks and BRCs with a single underlying asset}

We commence our analyses by comparing participant investment in stocks and the BRCs. Figure 3 depicts, with a box plot, the distribution of investment in stocks and BRCs with one underlying asset. The top (bottom) panel show those based on stocks with low (high) price volatility. For both panels, we first take the average investment in the same category for each participant and use it as an independent observation. For example, for stocks with low price volatility, we take the average investment in $\operatorname{Stock}_{L V 1}$ 
and Stock $_{L V 2}$. Similarly, for BRCs based on a low price volatility stock, we take the average investment in $\mathrm{BRC}_{L V, 70-1}$ and $\mathrm{BRC}_{L V, 70-2}$. In each panel, the results for students and the CFAs are shown separately. The box in the middle shows the $25 \%$ to $75 \%$ range with the median in the middle line, and the upper and the lower bounds correspond to the highest and the lowest amounts 12

As expected, the investment in stocks with high price volatility is significantly lower than the investment in stocks with low price volatility for both students and the CFAs. The median investment for high and low volatility stocks for students are 450 and 550 ( $<<0.001$, two-tailed Wilcoxon signed-rank (WSR) test), respectively, and those for the CFAs are 200 and 425 ( $\mathrm{p}=0.002$, two-tailed WSR). Similarly, students invest significantly more in stocks than the CFAs ( $\mathrm{p}=0.036$ for low volatility stocks and $\mathrm{p}=0.005$ for high volatility stocks, using a two-tailed Mann-Whitney test (MW)).

The top panel of Figure 3 indicates that there is no statistically significant difference between the investment for the low-price volatility stocks and the BRCs (with barrier price 70 ) created using the same stocks. 13 This suggests that the participants, both students and the CFAs, did not consider these BRCs to offer significant benefits or to introduce significant costs compared to the underlying stocks.

The bottom panel of Figure 3 shows that for stocks with high price volatility, students invest significantly more in the stocks than the $\mathrm{BRC}_{70} \mathrm{~s}$ (with barrier price 70 ), and significantly less than the $\mathrm{BRC}_{50} \mathrm{~s}$ (with the barrier price 50) created using the same high price volatility stocks. ${ }^{14}$ This suggests that students consider that $\mathrm{BRC}_{70} \mathrm{~S}$ intro-

\footnotetext{
${ }^{12}$ See Appendix $\mathrm{B} .1$ for the results for each product.

${ }^{13}$ The median investments in $\mathrm{BRC}_{70}$ based on the low volatility stocks are 550 for students and 400 for CFAs and are not significantly different from those in stock ( $p=0.800$ for students and $p=0.478$ for CFAs, two-tailed WSR test).

${ }^{14}$ The median investments by students are 450,350 , and 500 for high volatility stocks, $\mathrm{BRC}_{70} \mathrm{~s}$, and $\mathrm{BRC}_{50}$ s, respectively. $\mathrm{p}=0.066$ (stock vs $\mathrm{BRC}_{70}$ ), $\mathrm{p}=0.025$ (stock vs $\mathrm{BRC}_{50}$ ), and $\mathrm{p}<0.001\left(\mathrm{BRC}_{70}\right.$ vs $\mathrm{BRC}_{50}$ ), two-tailed WSR
} 
Figure 4: Probability estimates

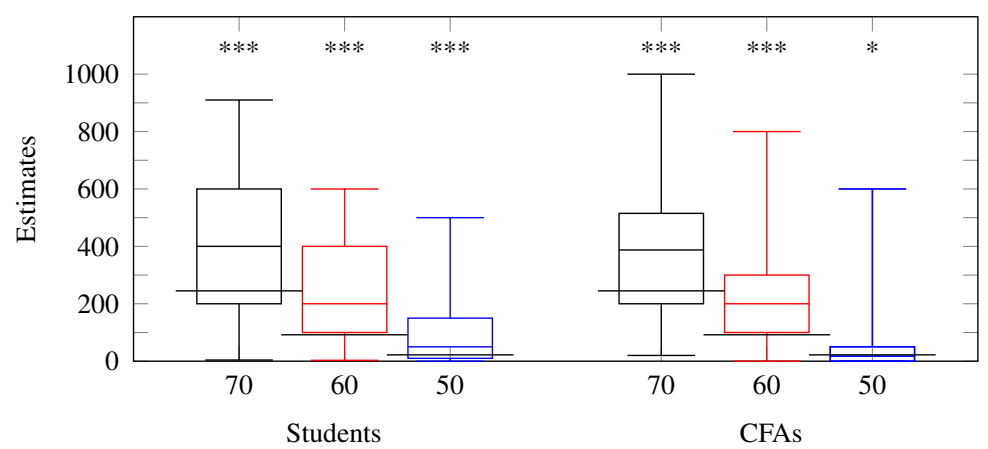

Horizontal bars represent the realized number of events based on 1,000 simulations.

$* * *, * *$, and $*$ denote the estimate is statistically significantly different from the realization of the model simulation at the $1 \%, 5 \%$, and $10 \%$ significance level using the two-tailed WSR test, respectively.

duces more cost than benefit compared to the underlying stocks, while the opposite is the case for $\mathrm{BRC}_{50} \mathrm{~s}$. For the CFAs, while there are no significant differences between the investments in the stocks and $\mathrm{BRC}_{70} \mathrm{~s}$, the investment in $\mathrm{BRC}_{50} \mathrm{~s}$ is significantly higher than for the underlying stocks. ${ }^{15}$ Thus, the CFAs also consider that $\mathrm{BRC}_{50}$ s offer more benefit than cost compared to the underlying stock with high price volatility.

Figure 4 illustrates the distribution, by the box plot, of the estimated frequency (out of 1,000) an investment in BRC results in a loss (i.e., the BRC returns the stock instead of cash) for three barrier prices $(70,60,50)$. As shown, the estimated frequencies are significantly higher than the outcomes of the stochastic model for both students and the CFAs and for all three barrier prices ${ }^{16}$ Thus, both students and the CFAs are more

\footnotetext{
${ }^{15}$ The median investments by students are 200,200 , and 400 for high volatility stocks, $\mathrm{BRC}_{70} \mathrm{~s}$, and $\mathrm{BRC}_{50}$ s, respectively. $\mathrm{p}=0.778$ (stock vs $\mathrm{BRC}_{70}$ ), $\mathrm{p}<0.001$ (stock vs $\mathrm{BRC}_{50}$ ), and $\mathrm{p}<0.001\left(\mathrm{BRC}_{70}\right.$ vs BRC $_{50}$ ), two-tailed WSR

${ }^{16}$ The outcomes of the model are 245, 92, and 22 for barrier prices 70, 60, 50, respectively. The corresponding median estimated frequencies for students are 400, 200, and 50, and those for CFAs are $387.5,200$, and 17.5 .
} 
"pessimistic" when compared to the stochastic model. We do not, however, observe any significant relationship between the estimated probability of loss and the preference for investing in BRCs over stocks (measured as the difference between the invested amount in $\mathrm{BRC}_{H V} \mathrm{~s}$ and $\left.\mathrm{Stock}_{H V} \mathrm{~s}\right)$. See Appendix B.2.

\section{Investment in Worst-of BRCs}

Figure 5 compares the distributions, by box plot, of the amount invested in $\mathrm{W}-\mathrm{BRC}_{70}$ and the minimum investment among three $\mathrm{BRC}_{70} \mathrm{~s}\left(\min \left(\mathrm{BRC}_{70}\right)\right)$ based on one of the three underlying stocks of the $\mathrm{W}-\mathrm{BRC}_{70}$. Note that the expected return of $\mathrm{W}-\mathrm{BRC}_{70}$ is the same as the worst among these three $\mathrm{BRC}_{70} \mathrm{~s}$. The left-hand side of Figure 5 shows that for students, the investment in $\mathrm{W}-\mathrm{BRC}_{70}$ is significantly higher than the minimum among the three $\mathrm{BRC}_{70}$ suggesting evidence of behavioral bias similar to the dieter's paradox $\sqrt[17]{17}$ For the CFAs, there is no significant difference between the two. ${ }^{18}$

Does the same behavioral bias continue to be observed even when the barrier price is 50? Figure 6 compares the distributions, by box plot, of the amount invested in W$\mathrm{BRC}_{50}$ and the average minimum investments among the two $\mathrm{BRC}_{50} \mathrm{~s}\left(\min \left(\mathrm{BRC}_{50}\right)\right)$ based on one of the underlying stocks that constitute the W-BRC $\mathrm{C}_{50}$. Note that we do not have participant investment for a BRC with a barrier price of 50, which has a low price volatility stock as its unique underlying asset ${ }^{19}$ Thus, $\min \left(\mathrm{BRC}_{50}\right)$ is based on the investment into $\mathrm{BRC}_{H V, 50-1}$ and $\mathrm{BRC}_{H V, 50-2}$.

\footnotetext{
${ }^{17}$ The median amount is 300 for $\mathrm{W}-\mathrm{BRC}_{70}$ and 200 for $\min \left(\mathrm{BRC}_{70}\right), p=0.002$ two-tailed WSR test. We regressed the difference between $\mathrm{WS}_{-} \mathrm{BRC}_{70}$ and $\min \left(\mathrm{BRC}_{70}\right)$ on the score of the financial literacy quiz and a constant for student participants. The estimated coefficient of the score is not statistically significant $(\mathrm{p}$-value $=0.927)$. See Appendix B.3

${ }^{18}$ The median amount is 100 for $\mathrm{W}-\mathrm{BRC}_{70}$ and 100 for $\min \left(\mathrm{BRC}_{70}\right), p=0.381$ two-tailed WSR test.

${ }^{19}$ This is because we implicitly assumed that investments for BRCs based on a high price volatility stock are lower than those for BRCs based on low price volatility stock.
} 
Figure 5: Investment in W-BRCs. Barrier price 70

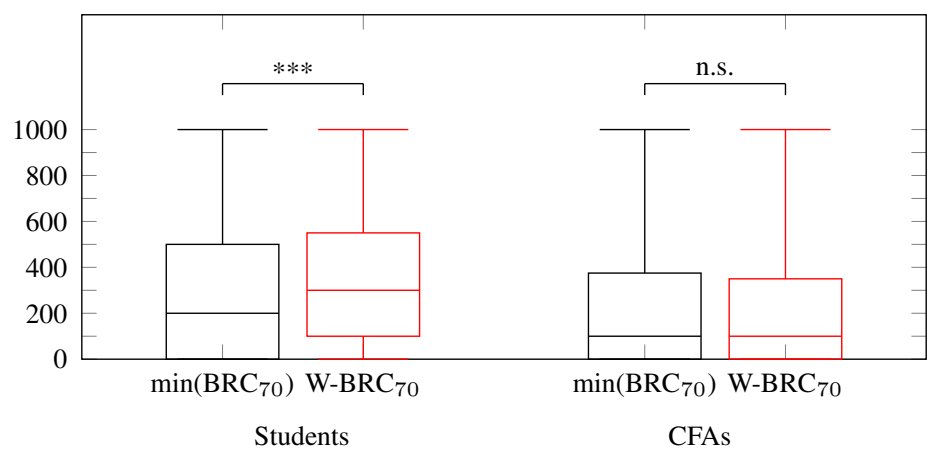

$\min \left(\mathrm{BRC}_{70}\right)$ refers to the minimum investment among the three $\mathrm{BRC}_{70}$ s each based on only one of the underlying stocks used in WS$\mathrm{BRC}_{70}$.

$* * *, * *$, and $*$ denote statistically significant difference at $1 \%, 5 \%$, and $10 \%$ significance level using the two-tailed WSR test, respectively.

However, we find that a nonnegligible number of participants (24 of 63 students and 25 of the 65 CFAs) invested less in a BRC based on a single low price volatility stock (either $\mathrm{BRC}_{L V, 70-1}$ or $\mathrm{BRC}_{L V, 70-2}$ ) than in those based on a single high volatility stock $\left(\mathrm{BRC}_{H V, 70-1}\right.$ and $\left.\mathrm{BRC}_{H V, 70-2}\right)$. For these participants, it is possible that comparing $\min \left(\mathrm{BRC}_{50}\right)$, which does not consider $\mathrm{BRC}_{L V, 50}$, and $\mathrm{W}-\mathrm{BRC}_{50}$ yields a biased result. We therefore compare $\min \left(\mathrm{BRC}_{50}\right)$ and $\mathrm{W}-\mathrm{BRC}_{50}$ for the restricted set of participants whose investments in $\mathrm{BRC}_{L V, 70-1}$ and $\mathrm{BRC}_{L V, 70-2}$ are higher than in $\mathrm{BRC}_{H V, 70-1}$ and $\mathrm{BRC}_{H V, 70-2}$.

The top panel of Figure 6 which is based on the unrestricted sample suggests that the behavioral bias is no longer observed, even among students when the barrier price is 50 instead of $70 .{ }^{20}$ However, in the restricted sample, we continue to observe the

\footnotetext{
${ }^{20}$ The median amounts for students are 500 for $\mathrm{W}-\mathrm{BRC}_{50}$ and 400 for $\min \left(\mathrm{BRC}_{50}\right)(\mathrm{p}=0.105$, twotailed WSR test). For CFAs, they are 250 for both $\mathrm{BRC}_{50}$ and $\min \left(\mathrm{BRC}_{50}\right)(\mathrm{p}=0.631$, two-tailed WSR test).
} 
Figure 6: Investment in W-BRCs. Barrier price 50
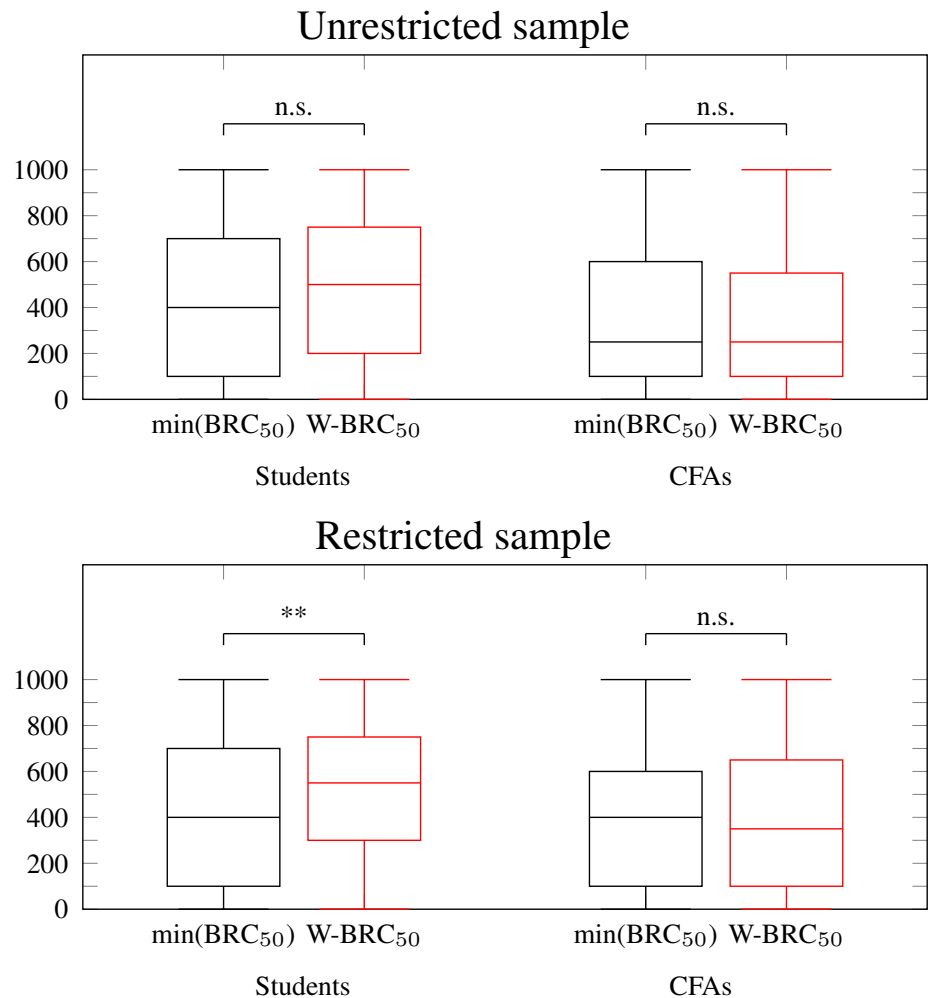

$\min \left(\mathrm{BRC}_{50}\right)$ refers to the minimum investment among the two $\mathrm{BRC}_{50} \mathrm{~s}$ each based on only one of the underlying stocks used in W$\mathrm{BRC}_{50}$.

$* * *, * *$, and $*$ denote statistically significant difference at $1 \%, 5 \%$, and $10 \%$ significance level using the two-tailed WSR test, respectively.

behavioral bias among students, even when the barrier price is 50.21

Let $\Delta_{B}^{i}=\mathrm{BRC}_{B}^{i}-\min \left(\mathrm{BRC}_{B}^{i}\right)$ be the observed degree of the behavioral bias a la dieter's paradox for participant $i$ when barrier price is $B \in\{70,50\}$. Note that it is a bias only when $\Delta_{B}^{i}>0$. Figure 7 shows the empirical cumulative distribution (ECD)

\footnotetext{
${ }^{21}$ In the restricted sample, the median amounts for students are 550 for $\mathrm{W}_{-} \mathrm{BRC}_{50}$ and 400 for $\min \left(\mathrm{BRC}_{50}\right)(\mathrm{p}=0.047$, two-tailed WSR test $)$. For CFAs, they are 350 for $\mathrm{BRC}_{50}$ and 400 for $\min \left(\mathrm{BRC}_{50}\right)$ ( $\mathrm{p}=0.627$, two-tailed WSR test). Furthermore, for the restricted sample of students, the financial literacy test score is negatively correlated with the difference between $\mathrm{W}-\mathrm{BRC}_{50}$ and $\min \left(\mathrm{BRC}_{50}\right)(\mathrm{p}$ value $=0.072$ ). See Appendix B.3.
} 
Figure 7: Distributions of $\Delta_{B}^{i}$

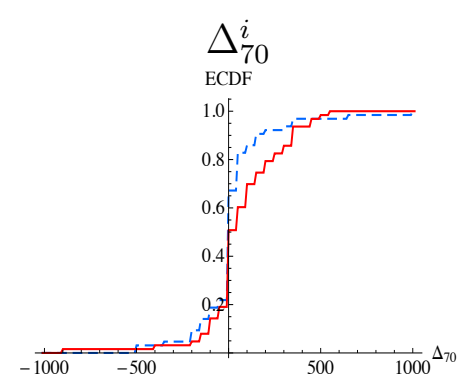

$p=0.047$

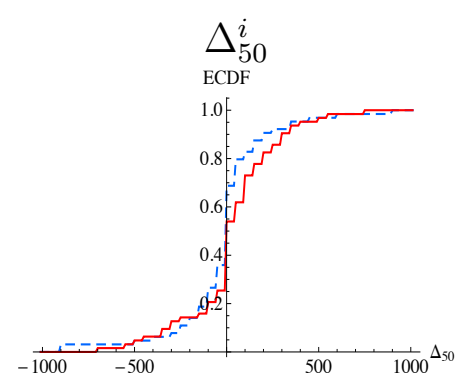

$p=0.105$

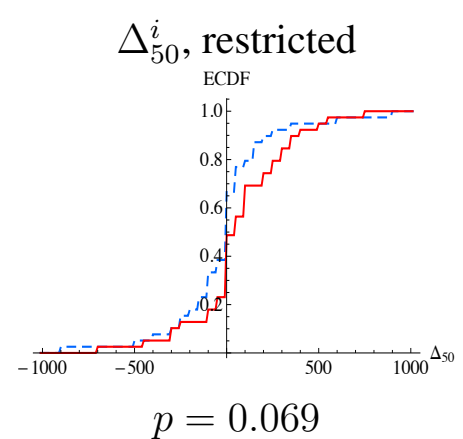

$p=0.069$

CFAs: dashed blue. Students: Red. p-values are based on the two-tailed MW test.

of $\Delta_{70}^{i}$ (left), $\Delta_{50}^{i}$ (center), and $\Delta_{50}^{i}$ for the restricted sample (right) for students (solid red) and CFAs (dashed blue). As can be observed for both CFAs and students, $\Delta_{B}^{i} \leq 0$ for a half of our sample for both $B=70$ and $B=50$. However, for remaining half, the distribution of $\Delta_{B}^{i}$ for students lie on the right of that for CFAs demonstrating, as we have seen above, the observed behavioral bias is larger of students than for CFAs. In particular for $\Delta_{70}^{i}$ and $\Delta_{50}^{i}$ for the restricted samples, the differences between CFAs and students are statistically significant at $5 \%$ and $10 \%$ level, respectively.

\section{Conclusion}

In this paper, we experimentally reexamine the bias found by Kunz et al. (2017) in investor risk perception regarding the structured financial products known as barrier reverse convertibles (BRCs) with worst-of payout characteristics.

Using an online survey of active capital market investors, Kunz et al. (2017) obtain support for the hypothesis that when relatively safe assets are added to risky assets to form the underlying assets of a BRC, investors erroneously perceive the risk of the BRC 
to fall when in fact it becomes higher. However, because participants in the survey did not face any monetary consequences from their stated estimates being accurate or not, this result may suffer from a hypothetical bias.

Employing an incentivized experiment with university students and CFAs, we found support for the result in Kunz et al. (2017) among student participants, but not among CFAs. These findings suggest that the effect of probability misperception $a$ la the "dieter's paradox" (Chernev, 2011) is likely to be observed among naive but not more sophisticated investors. Our results strengthen their evidence reported by Kunz et al. (2017) that the magnitude of the bias is smaller among those investors who have experiences in investing in BRCs. Just as we expect professional nutritionists to be able to evaluate calories without suffering from the "dieter's paradox," experts in financial analyses are able to evaluate the risk associated with the worst-of BRCs without suffering from a similar mis-perception.

Interestingly, Chernev (2011) shows that the "dieter's paradox" is stronger among those who are more concerned about managing their weight. Similarly, it is possible that the probability mis-perception reported in this paper is stronger among those investors who are concerned about managing returns on their investments. This question deserves a future investigation.

Future research could investigate how different ways of presenting the risk associated with complex financial products as BRCs can mitigate risk misperception by naive investors. See, for example, Anic and Wallmeier (2019) for such an investigation, an approach that would be of great importance in helping to protect investors.

There are other behavioral biases that have been proposed as an explanation for puzzling investments in structured financial products. For example, Castellano and Cerqueti (2013, 2018), in a stochastic dominance framework, argue that a mis-perception in 
trends is an important reason for investments in less profitable products. Future research that experimentally investigate other possible explanations would also be very fruitful.

\section{References}

ANIC, V. AND M. WALlmeIER (2019): "Perceived attractiveness of structured financial products: The role of presentaion format and reference instruments," Journal of Behavioral Finance, 21, 78-102.

Bernard, C., P. Boyle, AND W. Gornall (2011): "Lacally-capped investment products and the retail investors," Journal of Derivatives, 18, 72-88.

Castellano, R. And R. Cerqueti (2013): "Roots and effects of financial misperception in a stochastic dominance framework," Quality \& Quantity, 47, 3371-3389.

- (2018): "A theory of misperception in a stochastic dominance framework and its application to structured financial products," IMA Journal of Management Mathematics, 29, 23-37.

CÉlÉrier, C. AND B. VAllÉE (2017): “Catering to investors through security design: Headline rate and complexity," Quarterly Journal of Economics, 132, 1469-1508.

Chernev, A. (2011): “The Dieter's Paradox," Journal of Consumer Psychology, 21, $178-183$.

Chernev, A. AND D. GAL (2010): "Categorization effects in value judgements: Averaging bias in evaluating combinations of vices and virtues," Journal of Marketing Research, 47, 738-747. 
DÖBELI, B. AND P. VANINI (2010): "Stated and revealed investment decisions concerning retail structured products," Journal of Banking \& Finance, 34, 1400-1411.

Fernandes, D., J. G. L. JR., And R. G. Netemeyer (2014): "Financial Literacy, Financial Education, and Downstream Financial Behaviors," Management Science, $60,1861-1883$.

Henderson, B. J. AND N. D. Pearson (2011): "The dark side of financial innovation: A case study of the pricing of a retail financial product," Journal of Financial Economics, 100, 227-247.

Hens, T. AND M. O. Rieger (2014): “Can utility optimization explain the demand for structured investment products?" Quantitative Finance, 14, 673-681.

Holzmeister, F., J. Huber, M. Kirchler, F. Lindner, U. Weitzel, And S. Zeisberger (2020): "What Drives Risk Perception? A Global Survey with Financial Professionals and Lay People,” Management Science, 66, 3799-4358.

Hunt, S., N. Stewart, And R. Zaliauskas (2015): “Two plus two makes five? Survey evidence that investors overvalue structured deposits," Occasional Paper 9, Financial Conduct Authority.

Kahneman, D. And A. Tversky (1979): "Prospect Theory: An Analysis of Decision under Risk," Econometrica, 47, 263-292.

KunZ, A. H., C. Messner, And M. WAllmeier (2017): “Investors' risk perceptions of structured financial products with worst-of payout characteristics," Journal of Behavioral and Experimental Finance, 15, 66-73. 
Rieger, M. O. (2012): "Why do investors buy bad financial products? Probability misestimation and preferences in financial investment decision," Journal of Behavioral Finance, 13, 108-118.

VoKATA, P. (2021): “Engineering Lemons,” Journal of Financial Economics, forthcoming. 


\section{A Results based on full sample}

This Appendix reports the results based on the full sample by reproducing the Figures 3 to 7 in the main text as Figures A.1 to A.5. The qualitative results are the same as those reported in the main text, except that the dieter's paradox is observed (at the $10 \%$ significance level) for CFAs when the barrier is 70 , and the marginally significant difference in the magnitude of the dieter's paradox for the restricted sample when barrier is 50 becomes insignificant. Note, however, the observed magnitude of the dieter's paradox continues to be significantly larger for students than CFAs at $5 \%$ level when the barrier is 70 . 
Figure A.1: Amount invested. Full sample

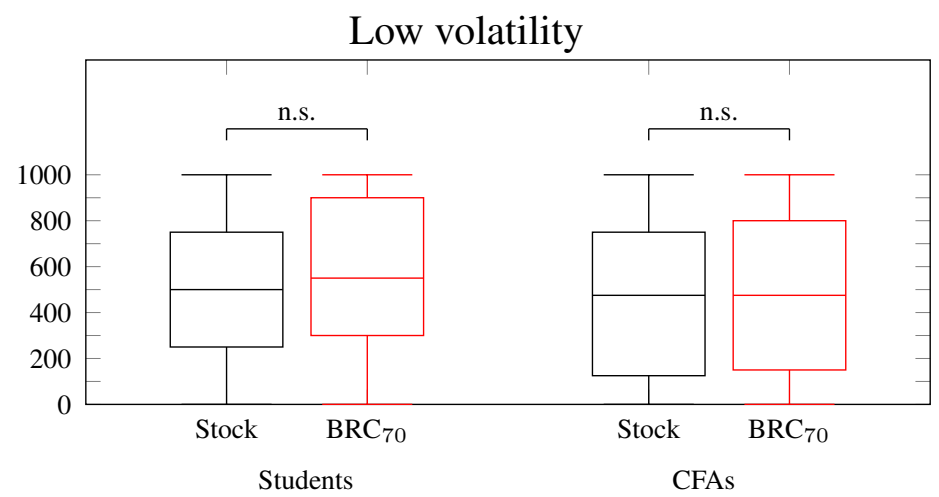

High volatility

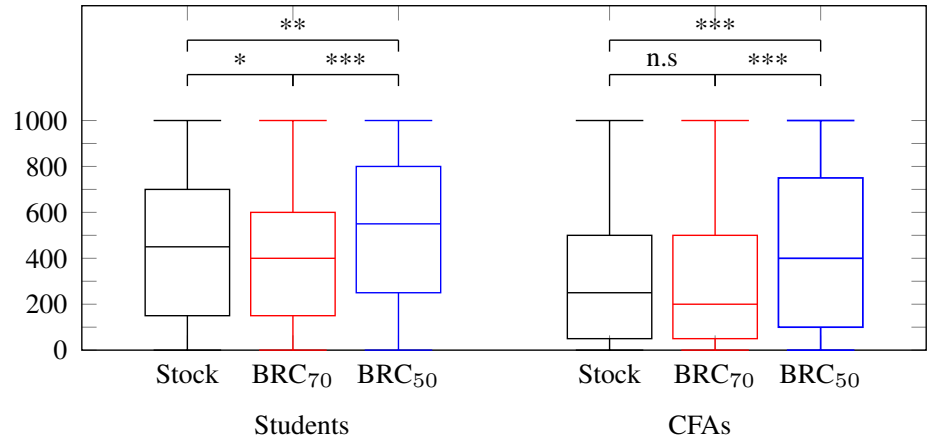

$* * *, * *$, and $*$ denote statistically significant differences at the $1 \%$, $5 \%$, and $10 \%$ significance level using the two-tailed WSR test, respectively. 
Figure A.2: Probability estimates. Full sample

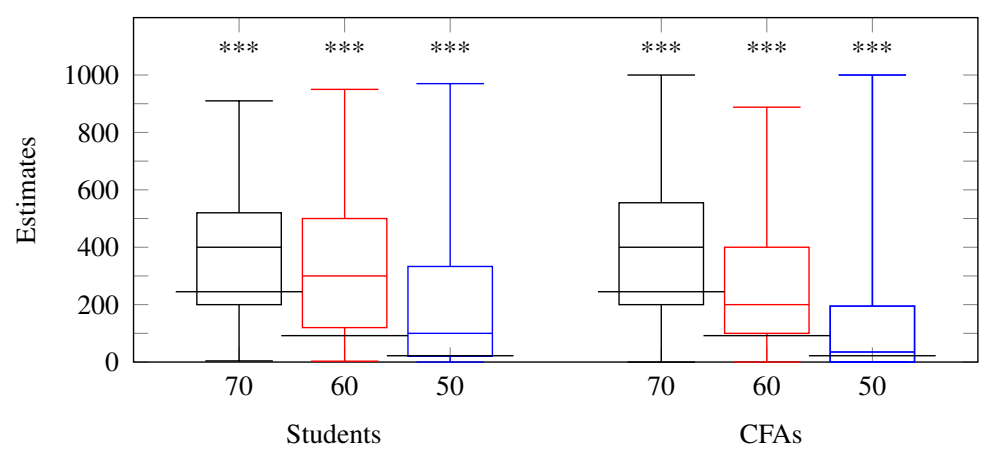

Horizontal bars represent the realized number of events based on 1,000 simulations.

$* * *, * *$, and $*$ denote the average estimate is statistically significantly different from the realization of the model simulation at the $1 \%, 5 \%$, and $10 \%$ significance level using the two-tailed WSR test, respectively.

Figure A.3: Investment in W-BRCs. Barrier price 70. Full sample

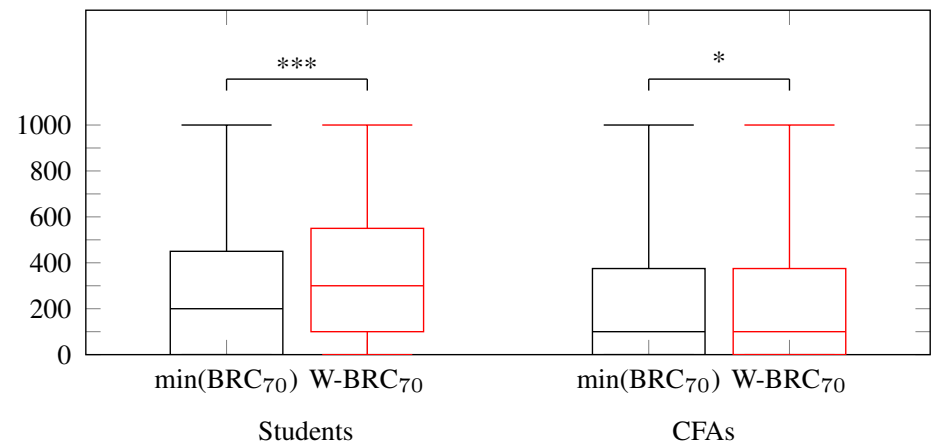

$\min \left(\mathrm{BRC}_{70}\right)$ refers to the minimum investment among the three $\mathrm{BRC}_{70}$ s each based on only one of the underlying stocks used in WS$\mathrm{BRC}_{70}$.

$* * *, * *$, and * represent statistically significant differences at the $1 \%$, $5 \%$, and $10 \%$ significance level using the two-tailed WSR test, respectively. 
Figure A.4: Investment in W-BRCs. Barrier price 50. Full sample
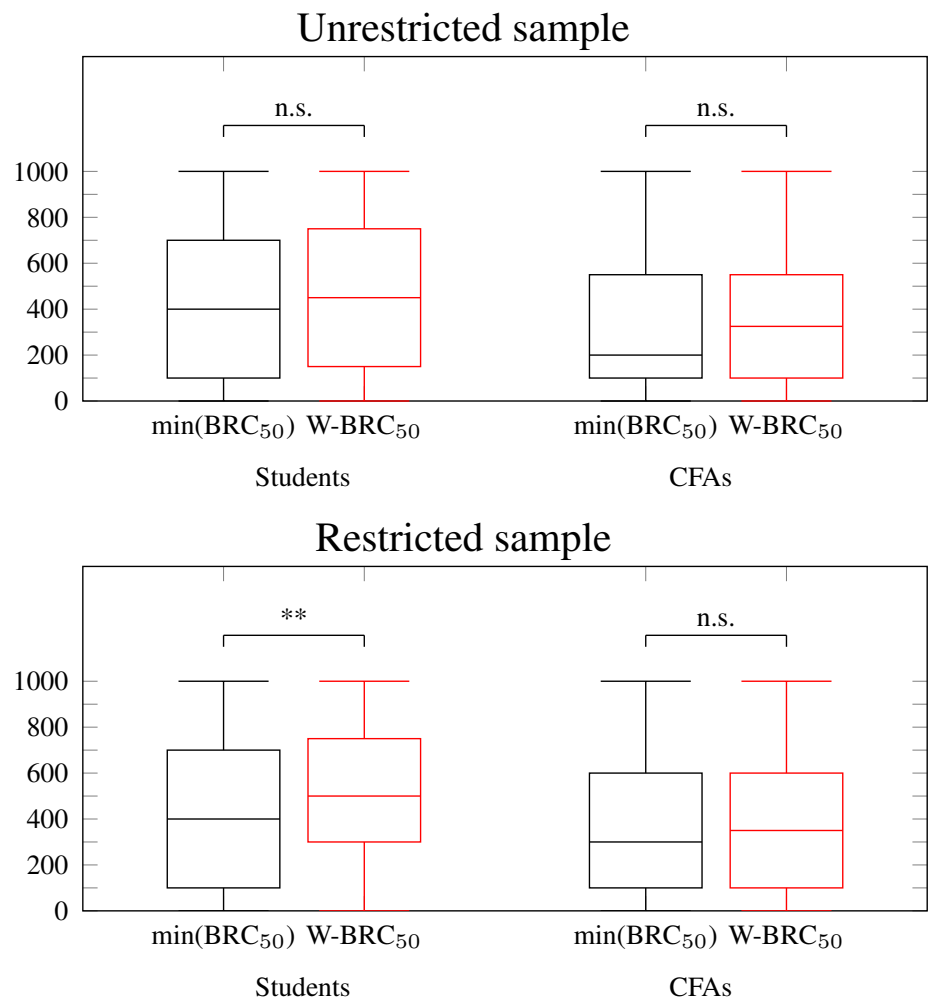

$\min \left(\mathrm{BRC}_{50}\right)$ refers to the minimum investment among the two $\mathrm{BRC}_{50} \mathrm{~s}$ each based on only one of the underlying stocks used in W$\mathrm{BRC}_{50}$.

$* * *, * *$, and * represent statistically significant differences at the $1 \%$, $5 \%$, and $10 \%$ significance level using the two-tailed WSR test, respectively. 
Figure A.5: Distributions of $\Delta_{B}^{i}$
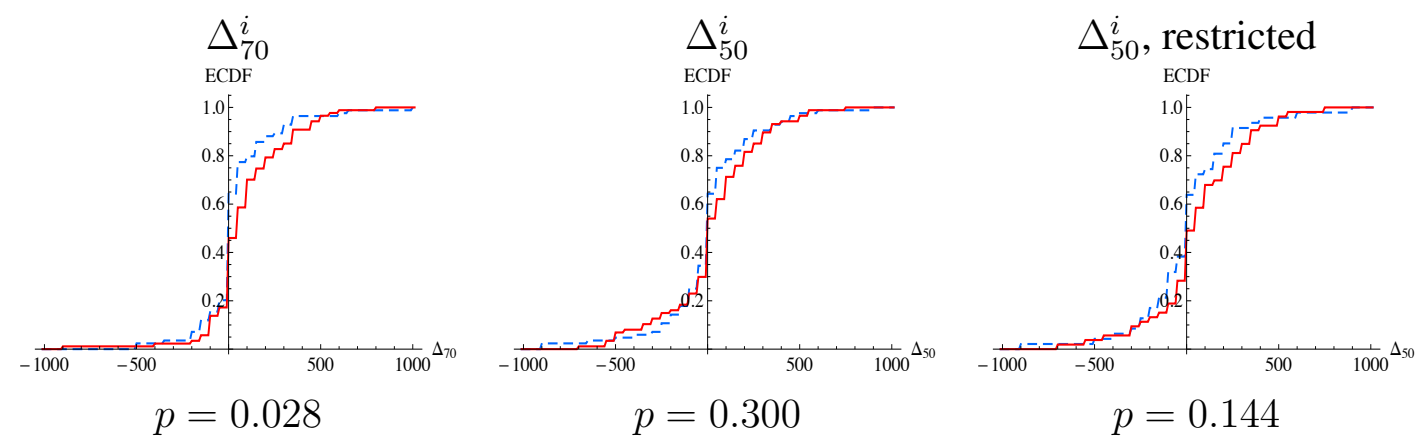

CFAs: dashed blue. Students: Red.

p-values are based on the two-tailed MW test. 


\section{B Additional results}

\section{B.1 Result for each product}

Figure B.1: Average amount invested.
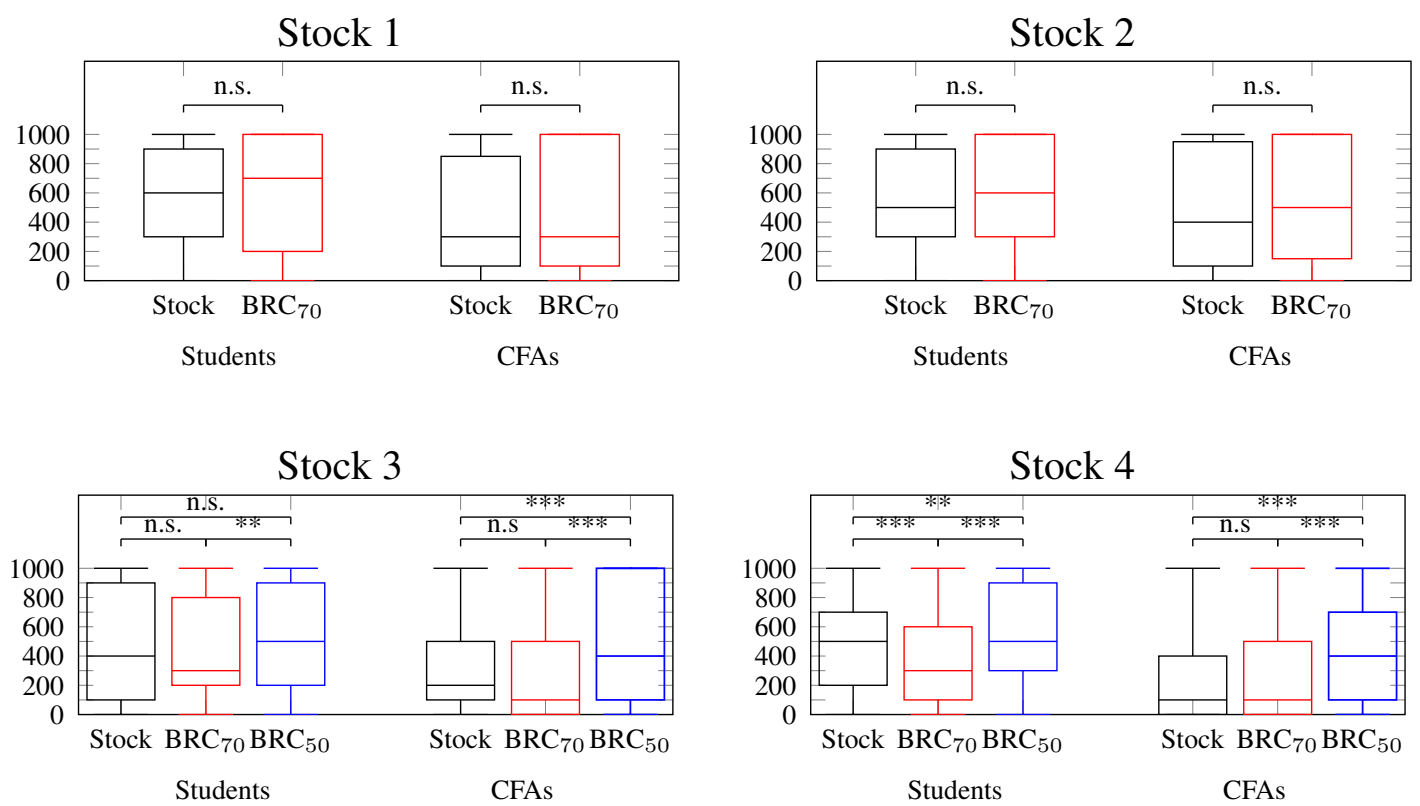

$* * *, * *$, and $*$ represent statistically significant differences at the $1 \%, 5 \%$, and $10 \%$ significance level using the two-tailed WSR test, respectively. 
Figure B.2: Investment in BRCs. Barrier price 70
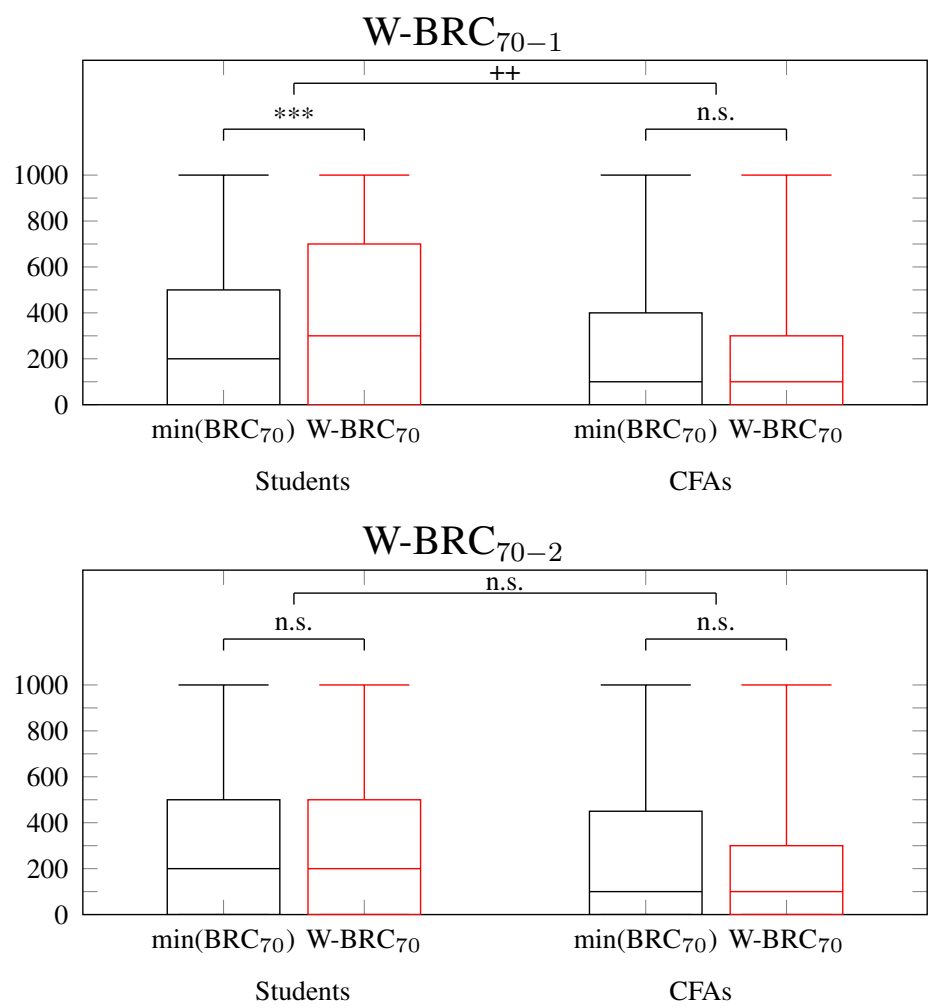

$\min \left(\mathrm{BRC}_{70}\right)$ refers to the minimum investment among the three $\mathrm{BRC}_{70} \mathrm{~s}$ each based on only one of the underlying stocks used in $\mathrm{W}$ $\mathrm{BRC}_{70}$.

$* * *, * *$, and * represent statistically significant differences at the $1 \%$, $5 \%$, and $10 \%$ significance level using the two-tailed WSR test, respectively.

,+++++ , and + represent statistically significant differences at the $1 \%$, $5 \%$, and $10 \%$ significance level using the two-tailed MW test, respectively. 
Figure B.3: Investment in BRCs. Barrier price 50. Unrestricted sample
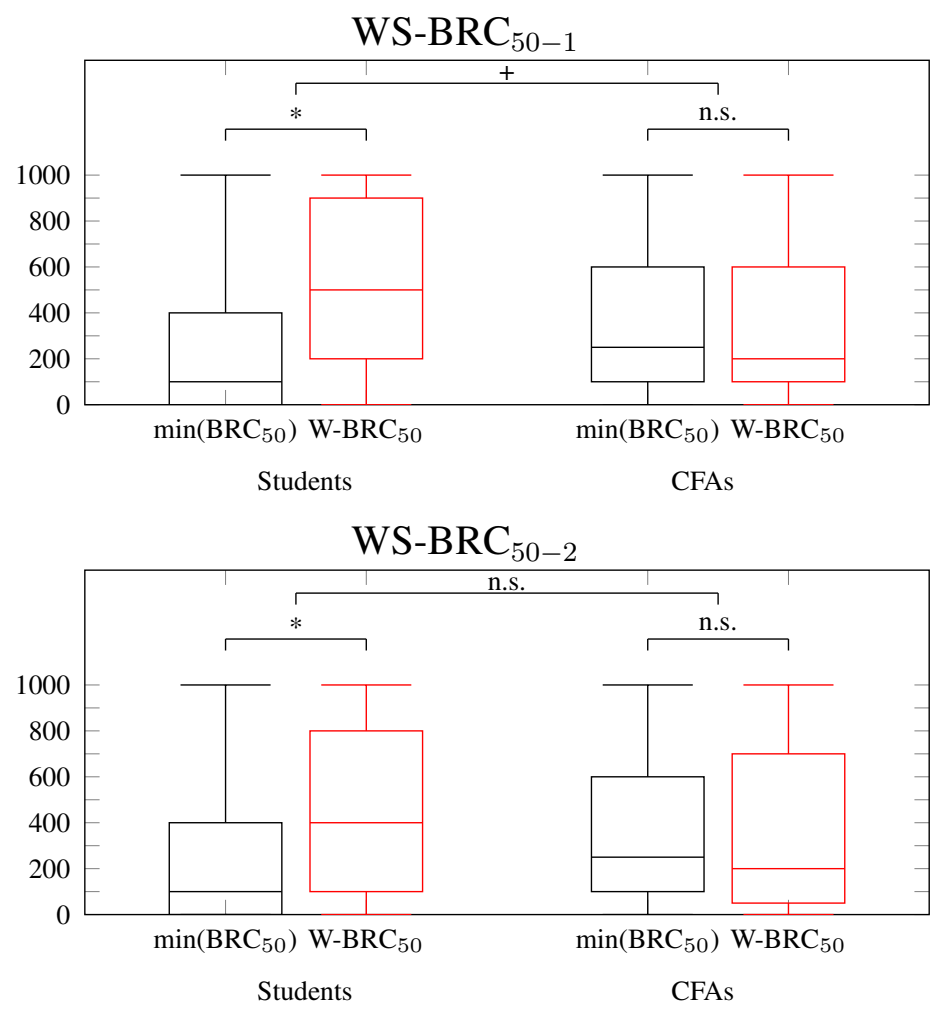

Note: $\min \left(\mathrm{BRC}_{50}\right)$ refers to the minimum investment among the two $\mathrm{BRC}_{50} \mathrm{~s}$ each based on only one of the underlying stocks used in W$\mathrm{BRC}_{50}$.

$* * *, * *$, and $*$ represent statistically significant differences at the $1 \%$, $5 \%$, and $10 \%$ significance level using the two-tailed WSR test, respectively.

,+++++ , and + represent statistically significant differences at the $1 \%$, $5 \%$, and $10 \%$ significance level using the two-tailed MW test, respectively. 
Figure B.4: Investment in BRCs. Barrier price 50. Restricted sample.
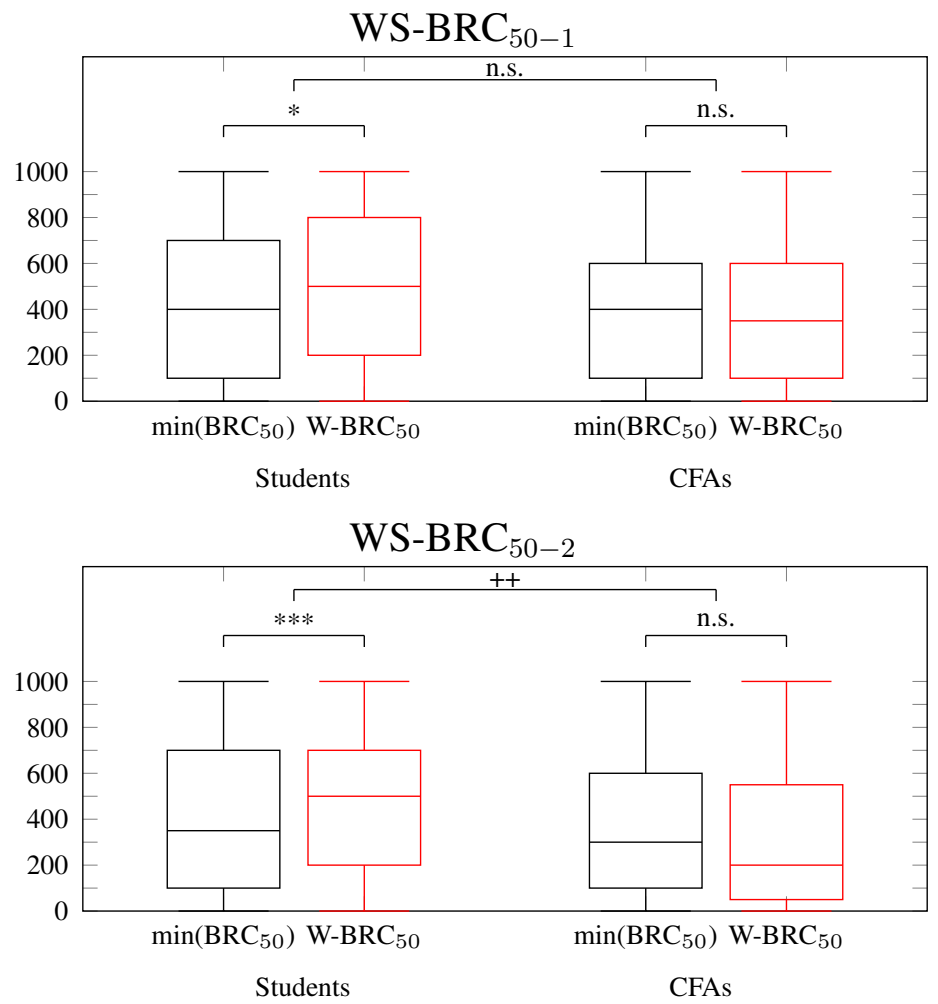

Only those participants whose investment to $\mathrm{BRC}_{L V, 70-i}>$ $\min \left(\mathrm{BRC}_{H V, 70-1}, \mathrm{BRC}_{H V, 70-2}\right)$.

$\min \left(\mathrm{BRC}_{50}\right)$ refers to the minimum investment among the two $\mathrm{BRC}_{50} \mathrm{~s}$ each based on only one of the underlying stocks used in W$\mathrm{BRC}_{50}$.

$* * *, * *$, and $*$ represent statistically significant differences at the $1 \%$, $5 \%$, and $10 \%$ significance level using the two-tailed WSR test, respectively.

,+++++ , and + represent statistically significant differences at the $1 \%$, $5 \%$, and $10 \%$ significance level using the two-tailed MW test, respectively. 


\section{B.2 Probability estimate and investment in BRC}

We regress the difference between the invested amount in the $B R C_{H V, B}$ and the high price volatility stock (averaged across two underlying stocks for each participant) on the estimated probability of losing the invested cash $\left(\operatorname{Pr}_{B}\right)$ for barrier price $B \in\{70,50\}$, a CFA dummy, and the interaction between the CFA dummy and $\operatorname{Pr}_{B}$. Further, in the third column, we regress the difference in the amount invested in the BRCs between $\mathrm{B}=70$ and $\mathrm{B}=50$, namely, $\triangle B R C=B R C_{H V, 50}-B R C_{H V, 70}$ on the difference in the estimated probability of losing the invested cash $\Delta P r=P r_{50}-P r_{70}$, a CFA dummy and the interaction between CFA and $\Delta P r$.

We do not observe any significant relationship between the probability estimates of losing the invested cash and any additional investment in BRCs over the stock. Note that the sum of the estimated coefficients for $\operatorname{Pr}_{B}$ and CFA $\times \operatorname{Pr}_{B}$ are not significantly different from zero ( $\mathrm{p}$-values are 0.120 for $\mathrm{B}=70$ and 0.215 for $\mathrm{B}=50$ ). 
Table B.1: Probability estimate and investment premium

\begin{tabular}{lccc}
\hline & $\mathrm{B}=70$ & $\mathrm{~B}=50$ & $\Delta B R C$ \\
\hline $\mathrm{CFA}$ & -45.38 & 74.79 & 20.51 \\
& $(69.58)$ & $(57.14)$ & $(73.53)$ \\
$\operatorname{Pr}_{B}$ & -0.16 & -0.11 & \\
& $(0.11)$ & $(0.26)$ & \\
$\mathrm{CFA} \times \operatorname{Pr}_{B}$ & $0.34^{* *}$ & 0.48 & \\
& $(0.16)$ & $(0.40)$ & \\
$\Delta \operatorname{Pr}$ & & & 0.003 \\
& & & $(0.14)$ \\
$\mathrm{CFA} \times \Delta \operatorname{Pr}$ & & & -0.003 \\
& & & $(0.20)$ \\
constant & 7.28 & 80.00 & 127.02 \\
& $(48.73)$ & $(42.86)$ & $(50.18)$ \\
\hline $\mathrm{R}^{2}$ & 0.083 & 0.054 & 0.002 \\
$\mathrm{~N}$ & 127 & 127 & 127 \\
\hline \hline
\end{tabular}

${ }^{* * *},{ }^{* *},{ }^{*}$ denote statistically significant difference from zero at the $1 \%, 5 \%$, and $10 \%$ level, respectively. Standard errors in parentheses. 


\section{B.3 Financial literacy and dieter's paradox among student partici- pants}

We report the results of regressing our measure of the dieter's paradox on student scores for the financial literacy quiz (FLQ) score. Our measure of the dieter's paradox of participant $i, D P_{B}^{i} \equiv \mathrm{W}-\mathrm{BRC}_{B}^{i}-\min \left(B R C_{B}^{i}\right)$ is the difference between the investment in W-BRC $C_{B}^{i}$ and the minimum investment among $\mathrm{BRC}_{B}^{i}\left(\min \left(B R C_{B}^{i}\right)\right)$ where $B \in$ $\{70,50\}$ are the barrier prices.

Table B.2: Financial literacy and dieter's paradox among student participants

\begin{tabular}{lccc}
\hline & $\mathrm{B}=70$ & $\mathrm{~B}=50$ & $\mathrm{~B}=50 \mathrm{res}^{+}$ \\
\hline FLQ score & 1.22 & -15.30 & $-41.57^{*}$ \\
& $(13.2)$ & $(15.14)$ & $(22.40)$ \\
constant & 59.39 & 162.10 & 436.15 \\
& $(116.56)$ & $(133.60)$ & $(201.42)$ \\
\hline $\mathrm{R}^{2}$ & 0.0001 & 0.0165 & 0.0851 \\
$\mathrm{~N}$ & 63 & 63 & 39 \\
\hline \hline
\end{tabular}

+: Restricted sample based on those with investment in $\mathrm{BRC}_{L V, 70-1}$ and $\mathrm{BRC}_{L V, 70-2}$ are higher than $\mathrm{BRC}_{H V, 70-1}$ and $\mathrm{BRC}_{L V, 70-2}$

***, ${ }^{* *},{ }^{*}$ denote statistically significant difference from zero at the $1 \%, 5 \%$, and $10 \%$ level, respectively.

Standard errors in parentheses. 


\section{Questionnaire}

\section{C.1 Financial literacy (students only)}

These questions are from Fernandes et al. (2014).

1) Imagine that the interest rate on your savings account was $1 \%$ per year and inflation was $2 \%$ per year. After 1 year, would you be able to buy:

- More than today with the money in this account

- Exactly the same as today with the money in this account

- Less than today with the money in this account

- Don't know

- Refuse to answer

2) Do you think that the following statement is true or false? 'Bonds are normally riskier than stocks.'

- True

- False

- Don't know

- Refuse to answer

3) Considering a long time period (for example 10 or 20 years), which asset described below normally gives the highest return?

- Savings accounts

- Stocks

- Bonds

- Don't know

- Refuse to answer

4) Normally, which asset described below displays the highest fluctuations over time? 
- Savings accounts

- Stocks

- Bonds

- Don't know

- Refuse to answer

5) When an investor spreads his money among different assets, does the risk of losing a lot of money:

- Increase

- Decrease

- Stay the same

- Don't know

- Refuse to answer

6) Do you think that the following statement is true or false? 'If you were to invest $\$ 1000$ in a stock mutual fund, it would be possible to have less than $\$ 1000$ when you withdraw your money."

- True

- False

- Don't know

- Refuse to answer

7) Do you think that the following statement is true or false? 'A stock mutual fund combines the money of many investors to buy a variety of stocks."

- True

- False

- Don't know

- Refuse to answer

8) Do you think that the following statement is true or false? 'A 15-year mortgage typically requires higher monthly payments than a 30-year mortgage, but the total interest paid over the life of the loan will be less." 
- True

- False

- Don’t know

- Refuse to answer

9) Suppose you had $\$ 100$ in a savings account and the interest rate is $20 \%$ per year and you never withdraw money or interest payments. After 5 years, how much would you have on this account in total?

- More than $\$ 200$

- Exactly $\$ 200$

- Less than $\$ 200$

- Don’t know

- Refuse to answer

10) Which of the following statements are correct?

- Once one invests in a mutual fund, one cannot withdraw the money in the first year

- Mutual funds can invest in several assets, for example invest in both stocks and bonds

- Mutual funds pay a guaranteed rate of return which depends on their past performance

- None of the above

- Don't know

- Refuse to answer

11) Which of the following statements is correct? If somebody buys a bond of firm B:

- He owns a part of firm B

- He has lent money to firm B

- He is liable for firm B's debts 
- None of the above

- Don't know

- Refuse to answer

12) Suppose you owe $\$ 3,000$ on your credit card. You pay a minimum payment of $\$ 30$ each month. At an Annual Percentage Rate of $12 \%$ (or $1 \%$ per month), how many years would it take to eliminate your credit card debt if you made no additional new charges?

- Less than 5 years

- Between 5 and 10 years

- Between 10 and 15 years

- Never

- Don't know

- Refuse to answer

\section{C.2 Other questions}

1) How much did you know about structured financial products before participating to this experiment?

- Almost none. Never heard of structured financial products.

- Not very much. Did not have much knowledge about structured financial products.

- More or less. Had a basic knowledge about structured financial products.

- Knew well. Could explain what are structured financial products in simple manner.

- Knew very well. Have researched on or worked with structured financial products in the past.

2) How often have you purchased structured financial product in the past 5 years?

- Never

- Once 
- Twice

- Three times

- Four times

- Five times

- Six times

- Seven times

- More than eight times

3) Please select all the assets you are currently investing in from the list below.

- Fixed term deposit

- Stocks

- Mutual fund

- Bonds

- Rare metals

- Real estate

- REIT

- Derivatives

- Arts and antiques

- Others (asked to specify in the next page)

- No investment

4) Please select your sex.

- Female

- Male

- Neither

- Prefer not to answer

5) Please provide your age. 